\author{
Charlotte Meierdirk \\ University of Portsmouth \\ School of Education and Continuing Studies \\ St George's Building \\ 141 High St \\ Portsmouth PO1 2HY \\ Charlotte.meierdirk@port.ac.uk
}

Title: The impact of the social environment on the student teacher's agency 


\title{
The impact of the social environment on the student teacher's agency
}

\author{
Abstract \\ This paper explores the agency of student teachers during the PGCE (Post/Professional \\ Graduate Certificate of Education) year at a higher education institution (HEI) in England. It \\ presents part of the findings of a yearlong investigation into the reflective practice of student \\ teachers during the PGCE year. The multi-method study includes surveying student teachers \\ $(n=101)$ and longitudinal interviews with student teachers $(n=6)$. One of the aims of the study \\ was to investigate the impact of the social environment on the student teacher. The research \\ analysis found that the complex environment the student teachers exist in can be both \\ supportive and constraining.
}

Keywords: teacher education, student teacher, agency, Bourdieu, social field, habitus Wordcount: 6997

\section{Introduction}

This paper presents part of a research project that investigated all the different dimensions of reflective practice, including reflection, critical reflection and reflexivity. Due to the amount of data the project created, this paper focuses on the latter two types of reflective practice and the impact the social environment has on the agency of the student teacher. The social environment of the school is an arena of accountability (Lindgren, Hanberger \& Lundström, 2016). When the student teacher is placed in an educational establishment they become agents of numerous arenas. In this paper, Bourdieu's (1998) social field theory has been used to analyse the complex relationship between agency and structure within teacher education with a focus on field, habitus and capital.

According to Flemmen (2013), the 'fields' are the various social and institutional arenas in which people express and reproduce their cultural competence and knowledge. There are many different 'fields' in existence, all 'historically constituted areas of activity with their specific institutions and their own laws of functioning' (Bourdieu, 1990, p.71). Bourdieu's social fields are a hub of social positioning and relationships among its members where the concepts of habitus and capital play key roles. 
Within schools, fields exist at macro and micro level from the school educational system at the macro level to the classroom at the micro (Burridge, 2014). Papers by Nolan (2012) and Ferrare \& Apple (2015) are relevant here as they focus on the interplay between educational structures of practice and agents. Nolan's (2012) work analyses teacher education in mathematics concluding how difficult it is for mathematics teachers to 'take risks' when trying to question the normal pedagogies in the subject. Whereas Ferrare \& Apple's (2015, p.53) theoretical paper encourages researchers to use field theory to evaluate 'the structures of practice and meaning in local educational contexts' such as schools.

Each field has its own rules that determine the conditions of entry and exclusion. Hence, one's own capital may be useful in one field but meaningless in another. The agents who belong to the field decide on the 'membership' requirements to join the field. The strategies used by the dominant group/person to maintain power are known as 'symbolic strategies'. This reproduction of the dominant agent is what Bourdieu (1984) refers to as symbolic capital. For example, in England, on a macro scale the National College of Teaching and Learning (NCTL) decides on the standards needed to qualify for Qualified Teaching Status (QTS) whereas at the micro level there may be many written and unwritten rules within a school environment. Within a school, the rules of the different social fields will shape the school's ethos, such as an individual needing to be a qualified teacher to belong to the school's staffroom (Wood, 2013).

Bourdieu's concept of habitus is interlinked to the concept of field and capital. Bourdieu posits the equation (Bourdieu, 1986, p. 101):

$$
[(\text { habitus })(\text { capital })]+\text { field }=\text { practice }
$$

Habitus is what causes a person to act and behave in a certain way; it is what makes them who they are. Habitus is fluid and is structured by the past and influenced by the future. It has a two way relationship with the social field and the teacher's position in that field. Habitus will change depending on the social field the agent finds themselves in but will correspondingly influence the field. The teacher's membership of these different social fields influences the way they act whilst simultaneously making adjustments to their habitus. It is the interaction between habitus, capital and field that results in practice. As Marton (2008, p.4) summarises: 
...practice results from relations between one's disposition (habitus) and one's position in a field (capital), within the current state of play of that social arena (field).

The relationship between the variables: habitus, capital and field, can be used to unpick different practices and in this case is used to help explain the practice of the student teacher.

The interaction between habitus, capital and field is key to this study and the extent the student teacher's habitus fits in the new social fields. Grenfell (2006) argued the interaction between field and capital is key to whether the student teachers succeed. He refers to a specific habitus for teaching: pedagogic habitus:

It is possible to explain teacher professional practice in terms of the interaction between their field contexts and their own habitus; or specifically those aspects of it which influence their pedagogic habitus. (Grenfell, 2006, p.2)

The student teachers will possess a pedagogic habitus consisting of past experience and belief. The student will need to adapt their pedagogic habitus under the influence of the new social fields and their expectations. A 'clash' will occur if the pedagogic expectations of these new social spheres do not align with the already held pedagogic habitus.

The relationship between field, habitus and capital is complex but can be used to understand the demands of certain fields and how to 'play the game'. Bourdieu (1990) refers to there being an adjustment of behaviour whilst adhering to the required behaviour of dominant agents within a field. Learning 'how to play the game' is an important part of the journey to professionalism of the student teacher and this paper explores these concepts and to what extent the student feels the need to adhere to the dominant agents in the different fields they encounter.

Capital plays an important function in the piecing together of field and habitus. The amount of influence an agent has within a social field is influenced by the amount of capital they possess which can be put simply as 'the currency of the field' (Grenfell, 2009, p.5). Agents will use their capital to become more influential and maintain their 'standing' in that particular social environment. The capital Bourdieu (1990) refers to is divided into four types: economic, social, cultural and symbolic and is collectively known as the 'species of capital'. Different capital may have more significance within different social fields and can be used to protect the existing 
power and rules that may be present. Economic capital is the wealth an individual has or has access to. An increase in wealth may lead an individual to have greater access to some social circles. Social capital is the capital received by being part of a social group, or a certain class. For the purpose of this paper cultural capital is most relevant. Cultural capital is the knowledge and skills acquired through either an embodied state, such as the knowledge of music, or an institutionalised form, such as educational credentials (Grenfell, 2008).

When the student teacher starts at their placement school they join a very complex environment where they face unique situations (Ulvik \& Smith, 2011). In the contemporary model of Initial Teacher Education (ITE) the student teacher is primarily accountable to their school mentor, professional mentor and university tutor. These agents have a direct influence over the student teacher and an interest in their performance (Gustafsson et al., 2015). Student teachers have yet to 'build up' the capital that is relevant to the field of teaching. They will have a degree and perhaps some school teaching experience but are not qualified teachers. Some of the more mature students come from high managerial positions in industry but the capital they possess will not have the same weighting in schools. This lack of capital can lead to frustration amongst student teachers.

\section{The use of reflective practice in ITE}

Finlay (2008) argues there are three approaches to reflective practice and these exist on a continuum ranging from reflection, through critical reflection to reflexivity (Fig. 1). The first stage is reflection which is reflection on practice and when a student teacher evaluates their own teaching and ways to improve. The next stage of the continuum is critical reflection which involves looking at the role of power within the social field the professional finds themselves in. The ultimate stage of the continuum is reflexivity which Loughran (2006, p.45) defines as "personal reflection" and the act of reflecting on one's own changing identity. 


\section{reflection}

\section{critical}

reflection

\section{reflexivity}

Figure 1: Reflective practice continuum (Adapted from Finlay, 2008, p.ix)

Reflective practice is a well-established feature in teaching education and plays an important role in teacher education (Meierdirk, 2016). Although reflective practice is interpreted differently by different teacher educators there are some areas of agreement and these are that reflective practice is the "process of learning through and from experience towards greater insights of self or practice" (Finlay, 2008, p.1). This 'process of learning' is the basis for all interpretations of the contentious term, and whatever form reflective practice takes the reflective practitioner should learn and grow from engaging with it. Student teachers engage in reflective practice within a complex environment.

\section{Research context}

This research is situated at a Higher Educational Institution (HEI) in South East England. The case study and questionnaire participants were part of the Post/Professional Graduate Certificate of Education (PGCE) programme. The PGCE is a full time, one year course that enables a graduate student to gain QTS. The HEI has a relatively small cohort of PGCE students with around 110 students enrolled every year. Seven different PGCE subjects are taught: English, Modern Foreign Language (MFL), Mathematics, Science, Business, Geography and Computer Science. The structure of the PGCE course is the same for all the courses. About one third of the PGCE year is spent at the university and the rest of the time the student teacher is in their placement(s).

After the first three weeks of the PGCE course the student teacher will start at their first placement (phase 1). After Christmas they start phase 2, with a placement in a different school, 
and after Easter, phase 3 in the same school as phase 2. The student teacher stays at the same placement for the last two teaching phases, unless there is a reason to move them to another school.

\section{Methodology}

Results from part of a study investigating the different aspects of reflective practice will be presented in this paper. The original study consisted of a case study involving 6 participants $(n=6)$. The case study participants were interviewed in total 21 times during the PGCE year. From the analysis of the interview data a questionnaire was devised to investigate the power constraints illuminated in the interviews. The questionnaire investigated to what extent different power constraints were common among all PGCE students $(n=101)$ and this part of the project will be focused upon here.

Results from the interview analysis found that there may have been a relationship between the Office for Standards in Education, Children's Services and Skills (Ofsted) grade of the placement school and the power asserted over the student teacher. Ofsted was founded in 1992 and has cultivated a strict inspection regime of schools and ITE which has brought with it greater accountability (Alexander, 2004; Hatcher, 2005; Thrupp, 2003). Ofsted is a nonministerial body that reports to parliament who inspects all schools, colleges, Early Years Providers and teacher educators in England. A new framework of inspection was introduced in 2015 that gave Ofsted the power to grade the different educational establishments as either: 'Outstanding', 'Good', 'Requires improvement' or 'requiring special measures'. Ofsted has the power to deem a school 'inadequate' which would trigger 'special measures' and lead to the replacement of the governing body and management of the school (DfE, 2016). Ofsted is an external stakeholder whose presence has led to an increase in the external accountability by the headteacher and governing body.

As argued by Courtney (2016), this accountability has also increased the internal accountability between the different levels of hierarchy within the school. Teachers are accountable to many different stakeholders. The teacher has 'hierarchical accountability' to Ofsted and 'professional accountability' for their lesson plans and assessment (West \& Roberts, 2011). The head teacher is accountable for many practices including: exam results, attendance, exclusions and finance. This accountability has led to an increase in performance measures that are present in the social 
fields of a school (Gustafsson et al., 2015; Mansell, 2007). This increase in performance measures is felt by the student teachers as they find themselves adjusting their teaching to meet Ofsted criteria.

From the interviews there was evidence different social environmental factors impacted on the student teacher and it was decided this relationship needed further research. The questionnaire is a common research method and can be used for large and small populations. It was used in this case to collect data from the total population of PGCE students $(n=101)$ across all subjects on the PGCE programme. The questionnaire of open ended questions was designed to collect data which could be compared to those obtained in the case study. The questionnaire, consisting of a combination of closed and open questions, were distributed at the end of the last PGCE lecture (June), which allowed access to all the student teachers assembled together.

The responses to the open ended questions were coded using descriptive coding. Descriptive coding is based on the subject area apparent in the narrative, such as talking about mentors or school policy (Saldana, 2009). The questionnaire results were coded and then analysed. After question 2 and 4 were analysed, four categories were established: mentor constraints, schools policy, facilities and personal constraints (Table 1).

Table 1: Discursive Codes

\begin{tabular}{|l|l|}
\hline Discursive coding & Codes \\
\hline Mentor constraints & Mc \\
\hline School policy & sc \\
\hline Facilities & F \\
\hline Personal constraints & Pc \\
\hline
\end{tabular}

Question 1 asked the PGCE student 'What was the name or Ofsted grade of your school?' in each Phase? The majority of students did not know the Ofsted grade of their school/college. Only six students wrote the Ofsted grade down for their first placement and only 5 knew the Ofsted grade for their second placement. It is possible some of the other respondents did know 
the Ofsted grade but chose not to state it. In the case of those respondents who stated an Ofsted grading, but not the name of the school/college, they were possibly protecting their own anonymity. The questionnaire was anonymous but had I wished to it may have been possible to discover who the respondents were by their placements. I did not do this and have kept the respondents' placements anonymous.

Questionnaires differ from interviews as it is the participant who records the answers, whereas with interviews the answers are recorded then transcribed. It is argued this distance reduces bias; however there may still be room for bias in the interpretation of those answers due to the subjectivity of the interpretation (Varga-Dobai, 2012). There were only a few answers to the questions which were ambiguous. For example, one respondent wrote there were no constraints to their teaching but then commented: 'I was allowed to teach the way I wanted but the school's department was quite old fashioned and didn't have modern teaching methods'. In this case, I had to make a decision as to whether the student teacher felt constrained in their teaching or not. I decided not, as they were still allowed to teach the way they wanted.

\section{Ethical considerations}

My research proposal was approved by the University of Portsmouth's Research Ethics Committee and I followed their guidelines. All Universities have drawn up their own detailed codes of practice and the University of Portsmouth is no exception. The University of Portsmouth's (2013, no page number) ethical code of practice states the following principles should govern research:

- respect the rights and interests of participants in the research, and to take account of the consequences for them.

- respect individuals as autonomous agents with rights regarding decision and choice, and to conduct research on the basis of informed consent.

- reflect on the broader social and cultural implications of the research.

It was important the participants had the right to their own destiny and the right of selfdetermination. I achieved this through considering the participant's right of informed consent, beneficence, privacy and confidentiality, right to fair treatment and the right to be informed of any benefits. 


\section{Interview analysis}

The original research case study included semi-structured interviews. From analysing the interview data it was found that those student teachers who were placed in an 'outstanding' school had more pressure on them than those in lower graded schools. For example. Student D who taught in an 'outstanding' school commented:

.. yeah, I'd say my mentors.....I can't fault their idea of best practice and their grades prove that it works and you see the kids' books and you see... and it works, it's just... what I, I'm struggling to kind of ... fully embrace it because I can see that it works but it's just not my, my way... my idea, my ethos of teaching. (Student D)

And when asked about the teaching in the department he said:

It's... I would have to say it's overly structured and overly regimented with not a lot of innovation or independent thought-provoking going on which is kind of the exact opposite of how I like to run my lessons and how I see education. I want to try different things and... I just think sometimes I'm kind of pushed down... Look, I'm used to this... these are standards, these are requirements, we need to hit them, and I completely understand that and I know I need to do that to pass the course, it's like that with anything but... I like to try different things and just... not be creative, innovative, to the point that everyone goes, 'Wow, I was blown away by a lesson,' but just try something different not only for the class but for me and I do feel I get a little bit held back. (Student D)

Student D highlighted the impact of his school mentor. He understands school mentors are good teachers but they have 'formulas' to their lessons that he would rather not adhere to. He knows teaching in the mentor's style of lesson achieved good grades but he would have liked to try more innovative teaching. In this instance, the mentor is restricting the student teacher's teaching but these restrictions are there because the mentors themselves are 'controlled', to some extent, by the educational structures they work within and can be argued take the form 
of symbolic violence, as Ofsted create an environment of performance discourse that becomes embedded into teaching practice.

Student A stated:

I always feel that as an adult if you're wrong you should admit you're wrong and you should always treat children with respect, and I just feel a little bit sometimes that, you know, balling them (the students) out over things just to make the point that you rule the classroom, which I can see exactly why you have to, it doesn't fit with who I am. So that would probably be the thing that would stand between me...(and the way I want to teach). (Student A)

Student C stated:

I think at the beginning I thought that teachers...the whole environment would be much more (supportive)... it wouldn't be as target driven and so egotistical as I thought the business environment was and I'm starting to realise that may not be the case.

The student teachers share common experiences across the school/college placements but it is their habitus that will cause the trainees to react and behave differently. All the student teachers possess different habitus made up from various backgrounds and experiences. The habitus will itself be formed from the rules, powers and social fields that the student teacher engages with. Although the social structures impact on the student teacher, they still have agency. The interview analysis found students have a pedagogic habitus that they try to preserve during the PGCE year and so there is not complete determinism.

\section{Questionnaire analysis}

The questionnaire was intended to further discover the different constraints on the PGCE student and whether some of the relationships, between the student and the placement school, were apparent across all PGCE students. It was found that the relationship between the Ofsted grading, of the placement school, and the types of constraints the student teacher experienced, needed further investigation. There was evidence of different social environmental factors that impacted on the student teacher and it was decided this relationship needed further research. 
A questionnaire was devised to investigate the power constraints illuminated by the case study interviews and to what extent they were common among all PGCE students.

Table 2: Relationship between constraints and Ofsted grade for all phases (\%)

Constrained Unsatisfactory Satisfactory Good Outstanding Total

$\begin{array}{llllll}\mathrm{Y} & 2 & 33 & 44 & 21 & 100 \\ \mathrm{~N} & 5 & 30 & 38 & 28 & 100\end{array}$

Table 2 shows the relationship between the Ofsted rating/grade of the school placement and the perceived constraints on the teaching of the PGCE student. Table 2 presents the same data as percentages linked to phases 1 and 2. After correlating phase 1 and 2 there were no obvious trends and so phase 1 and 2 were accumulated to judge any overall relationship. The evidence from Table 2 indicates there is no relationship between constraints and Ofsted grading. For example, out of those students who felt constraints on their teaching, 2 were in 'unsatisfactory' schools, $33 \%$ in 'satisfactory', $44 \%$ in 'good' and $21 \%$ in 'outstanding' schools. The extent of the constraints within the school environment does not have a direct relationship with the grading of the school; however 63 students were placed in outstanding and good schools and felt some constrains on their teaching.

The second and fourth question on the questionnaire asked the student teacher 'Was there anything that stopped you from being the teacher you wanted to be? If yes, what was it?' The results were coded simply into 'yes' or 'no' and Table 4 shows the results for phase 1 of the teaching practice. In phase 1, 39 student teachers felt their teaching was constrained and 62 did not (Table 3).

Table 3: Number of students feeling constrained in teaching in phase $1(\mathrm{~N}=101)$ 


\begin{tabular}{llllll}
\hline & & Frequency & Percent & Valid Percent & Cumulative Percent \\
\hline Valid & yes & 39 & 38.6 & 38.6 & 38.6 \\
& no & 62 & 61.4 & 61.4 & 100.0 \\
& Total & 101 & 100.0 & 100.0 & \\
\hline
\end{tabular}

Table 4: Number of students feeling constrained in teaching in phase $2(\mathrm{~N}=101)$

\begin{tabular}{llllll}
\hline & & Frequency & Percent & Valid Percent & Cumulative Percent \\
\hline Valid & yes & 53 & 52.5 & 52.5 & 52.5 \\
& no & 48 & 47.5 & 47.5 & 100.0 \\
& Total & 101 & 100.0 & 100.0 & \\
\hline
\end{tabular}

In phase 2, 53 student teachers felt constraints on their teaching (Table 4). It is possible this is due to the schools having more influence on the ways the students taught or was due to the student having more experience and therefore greater knowledge of teaching. As the student teachers gained in confidence they were more likely to try out new ideas and therefore felt more constrained in their second placement.

Table 5: Cross tabulation of phase 1 constraints and phase 2 constraints $(\mathrm{N}=101)$ Count

\begin{tabular}{lllll}
\hline & & \multicolumn{2}{l}{ Constraints phase 2 } & Total \\
& & yes & No & 39 \\
\hline Constraints phase 1 & Yes & 20 & 19 & 62 \\
& No & 33 & 29 & 101 \\
\multirow{2}{*}{ Total } & & 53 & 48 & \\
\hline
\end{tabular}

Table 5 shows the cross tabulation of the student teachers' answers to question 2 and 4: 'Was there anything that stopped you from being the teacher you wanted to be?' The results were coded simply into 'yes' or 'no' and a cross tabulation calculated between the two phases. The 
results from Table 5 show the majority of student teachers felt their teaching had been inhibited in some way in one or both of their placements. In fact, just over 70\% $(20+19+33=72)$, felt something stopped them from teaching the way they wanted to in at least one of their placement schools and there was a dominant pedagogic habitus they were expected to adhere to. On the positive side, $30 \%$ (29) of the students felt they were not constrained and could teach the way they wanted to in either placement. This stresses the importance of having two placements as the data is evidence that a student teacher will be more likely to have the freedom to be innovative if they are placed in different schools. In different placements the student teacher will experience different social environments. The more experience the student has, of different social fields, the more cultural capital they will accumulate that will give them more agency over their evolving pedagogic habitus.

A number of students liked the freedom and support they received:

I had the freedom to be creative and experimental.

My mentors were outstanding and encouraged me to experiment with different strategies.

Lots of different teaching styles in department so good to develop my own style...

Having access to different teaching styles and allowing the student teacher the freedom to develop their own style is seen as important to the student teacher, but the results show only 29 found this freedom in both placements. Interestingly, in the second placement more student teachers felt they had less freedom even though they were now more experienced. Whether this 'lack of freedom' was due to an increase in constraints on their teaching or due to the student being more aware of the constraints is unclear, but more student teachers felt less freedom in their second placement and greater conflict in their pedagogic habitus.

Out of all the placements there were a number of student teachers who were placed in the same school but in different departments. There were also some departments who had a different PGCE student in phases 1 and 2. Due to some students not recording the name of their school/college it was hard to have a definitive figure of those schools that had more than one PGCE student, but there were certain trends. Two of the most popular schools, to be placed in across subjects, did have consistent findings. Two schools: school X and Y had five PGCE students placed with them across the two phases and across subjects. With school X, four of 
the PGCE students felt constrained and with school Y, four felt they were allowed a lot of freedom in their teaching. With these two schools the way the student teachers felt was not limited to their department or their particular placement phase. With school Y, where students felt constraints on their teaching, the comments made by the students were similar:

The department weren't very approachable or helpful so I didn't feel like I could experiment with teaching.

And..

The school had a specific structure to follow for each lesson regardless of the class. The mentor wanted things done a certain way and would relate my teaching practice to hers therefore I felt I had to teach the same.

According to the questionnaires, three of the PGCE students, across all the courses, actually had three placements. With one of those students they went back to their first placement in phase 3 and for the other two they went to a completely different school for the last phase. With all three students they felt 'overly' constrained in their second placement. One student commented: 'I had to follow a structure identified by my mentor. I felt on edge when teaching in front of him'. There are a few unknowns with these three students. For example, had they been 'failing' students', one would have expected them to have less freedom in the class. Mentors would have had greater presence, in their classes, and control over their teaching.

\section{Types of constraints}

Table 6 illustrates the factors, derived from the questionnaire, which constrained students' teaching. The results show the strong influence of the school mentor.

Table 6: Influences on student teachers

\begin{tabular}{ll}
\hline Reason & Percentage (\%) \\
\hline Mentor Constraints & 57 \\
School Policy & 20 \\
Facilities & 16 \\
Personal Constraints & 7 \\
\hline
\end{tabular}


These results may not be surprising because of the key role of the mentor; however, the student teachers distinguish between a mentor supporting them and acts that constrained them. The following quotes were fairly typical responses with regards to how mentors influenced the student's teaching:

I felt like I had to produce lessons my mentor would approve of (i.e. give lessons in his own style) in order to get a satisfactory Doc 9 (lesson observation). He didn't like it when I tried new things, ideas or differentiated.

And...

I had to teach the way my mentor did. I had to use the school's lesson plan and follow the school's scheme of work completely. If my mentor thinks he would have done something a different way to how I did it he would grade me unsatisfactory.

These comments were not uncommon and showed that some mentors, although supportive, had expectations that the student teacher should teach like them. The student teachers wanted to keep their mentors happy and so they changed their teaching style to be similar to their mentors. There was a belief, among the students, that by teaching in a similar way to the mentor they would receive higher observation grades and so the student teacher's pedagogic habitus was heavily influenced, if not dominated, by that of the mentor's.

Teaching in a similar way to the mentor was not the only constraining factor. A number of students said they could not be who they wanted to be: 'I didn't feel like I was able to show my personality in lessons'. This comment correlates with one of the conclusions from the case study interviews that student teachers had to be a different person in class. In the case study it was found that it was not until the student had more confidence that their 'usual' personality could be known.

Some students felt the department they trained in was not welcoming and it made them feel like an outsider:

Relationships with other members of staff were not easy to establish, which made me feel an outsider within the school. 
Social integration into the department is important to student teachers. If the social induction is hard then the student teacher feels like an 'outsider'. It is possible the mentors and other members of staff need to find a way to exert power over the student and distancing themselves is certainly one way of doing this. The subject department will have its own 'field of play' and within that field there will already be 'rules of the game'. The student teacher has to fit into an already established field and discover its rules. They will have less cultural capital with which to influence the decisions within that field. This situation is the same for all PGCE students but some departments may be less accepting of a new agent within 'their' field.

Lack of facilities was a reason why $17 \%$ of student teachers could not teach the way they wanted, with lack of ICT facilities being the most common reason:

..(there was a) lack of working printers, photocopiers to produce resources, shortage of papers, board pens, text books etc...

A number of trainees were denied access to:

...working computers, printers, photocopiers etc... and also being denied access to these resources when they became available.

The student teachers commented about it being a privilege to have access to some of these resources. This made them feel like 'outsiders' or 'second class citizens'. The restriction on using resources and access to computers is an example of Bourdieu's (1977) power within a field of play. Social and cultural capital is being used to gain access to resources: 'Bourdieu compares the structure of a field to that of a poker game where the pile of chips reflects the unequal distribution of capital that both summarizes the results of previous struggles and orient strategies for the future' (Bourdieu \& Wacquant, 1992, pp. 98-99). The amount of capital the student teacher has will determine whether they will be subordinate or dominant within a field. In this case, the students have less social capital, as they are new to the placement school, and they also have less cultural capital as they are yet to qualify as teachers.

Too much reliance on 'Ofsted' grading was identified as the second most common factor affecting the students' teaching: 
There was an over reliance on the Ofsted grading of an 'outstanding' lesson which meant all lessons had to stick to an unrealistic plan at all times that restricted creativity within the classroom for both teacher and pupils.

Ofsted is an external body that schools are accountable to, but the impact of Ofsted requirements run down the school hierarchy, and affect all members of the educational establishment. Some schools have rigorous frameworks for the teachers and student teachers to work within. These policies help the school achieve their desired Ofsted grade but restrict the teaching practice.

\section{Positive experiences}

Not all the comments were negative on the questionnaire. As illustrated in Tables 3 and 4, around $50 \%$ of the student teachers felt they had freedom to teach the way they wanted in at least one of the teaching phases. Some student teachers commented on what they thought was good about their mentoring and this is important in recognising what makes a good placement. The most frequent comment was to do with the freedom to teach the way the student teacher wanted and to try different pedagogies:

I was allowed to teach exactly as I wanted. I was encouraged to take my own path. I was offered feedback on my lesson plans and a couple of times I changed them.

And other similar comments:

I had complete freedom to be the teacher I wanted to be.

The school was brilliant. I was supported by the mentor and could teach and develop at my rate.

The teachers let me develop my own style

The students who were happier with their placements were supported but also allowed freedom to develop their own teaching style. This scenario is very important to the PGCE students as they want to develop their own teaching styles by trying out new ideas, rather than just being told what works for the mentor and having to conform. 


\section{Conclusion}

Analysis of the questionnaire showed there were many social fields that the student teacher belonged to, both at a macro and micro level (Fig. 2). There are various agents, within these social fields, that will dominate and control the 'rules of the game'. Those dominant agents possess more of the relevant capital that allows them to be more influential. The questionnaire showed how important cultural capital is within the placement schools, at both the macro and micro level.

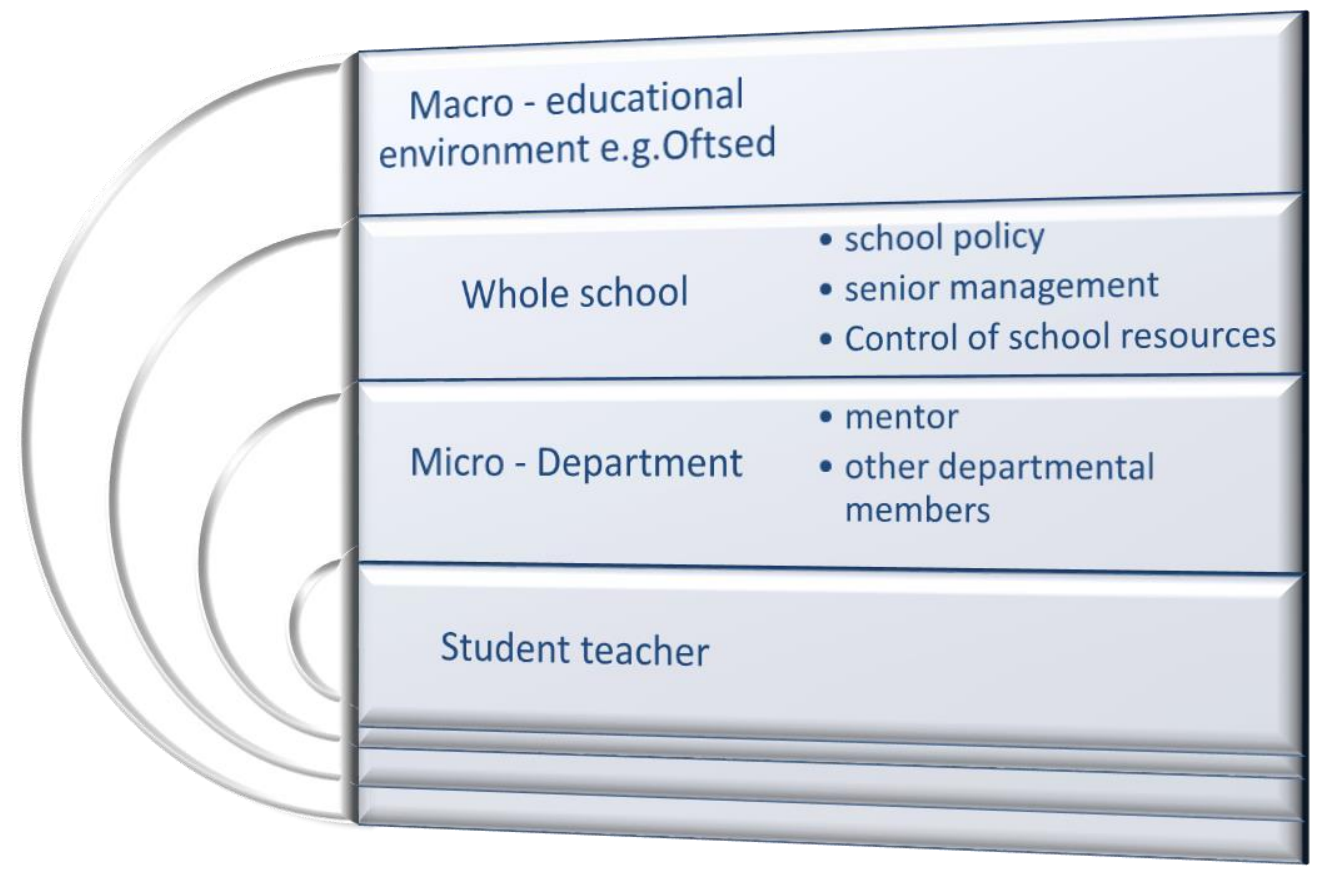

Figure 2: Different fields of the student teacher

At the micro level, the very person who reflects with the student (the mentor) influences the student teacher but for some student teachers mentors are restricting their innovation as they are being 'held back' and 'having to teach a certain way'. The different 'fields of play' have rules and 'internal logic' and the student teacher may find they do not have the capital to influence the field. This is shown with the majority of student teachers having to teach the way the mentor requires: 'the mentor wanted things done a certain way.....and I felt that I had to teach the same (way)....' This reproduction of the same pedagogic habitus takes the form of 
symbolic capital and to some extent symbolic violence as it is the reproduction of the status quo by a dominant agent.

This symbolic violence relies on the student teacher accepting and following the rules, which they generally do, so as not to upset their mentors and the consequence of perhaps receiving lower grades. If the student's pedagogic habitus does not fit with their placement then they become a 'fish out of water'. At one end of the scale of conflicting pedagogic habitus, the student may compromise and accept the change; and at the other end, the student may leave the course because they are not willing to change. This changing pedagogic habitus is reinforced through the constant use of reflective practice. In teacher education, reflective practice generally happens with the mentor or university tutor and so the dominant pedagogic habitus can be reproduced.

Within the social field of the 'whole school' some student teachers were made to feel unwelcome or were restricted when accessing resources, such as not allowing the use of the departmental photocopier or printer. These limits are placed on the student teacher by agents that have more capital in that particular field. As Nolan (2012) argued. the student teacher will feel more comfortable in the field that best matches their habitus, even though both habitus and field will be evolving all the time. Student teachers have yet to obtain the status needed to have influence in those fields and are still learning how to 'play the game'.

The power exerted at the macro level by external agents, such as Ofsted, impact both directly and indirectly on the student teacher. The questionnaire data showed that Ofsted's grading of lessons caused pressure and stress for the students and there was an 'overreliance on Ofsted grading...that restricted creativity'. Senior management is accountable to Ofsted for grades and attainment but the teacher is responsible for meeting the targets (Courtney, 2016; Mansell, 2007). This responsibility and accountability is being felt by the student teachers. As Student A quoted '...I thought the whole environment...wouldn't be as target driven...' The agency of the student teacher is being limited from a number of areas: the mentor, other teachers, school management and Ofsted. Some of these limiting factors are 'a priori' and independent of the individual. Ofsted is a structure that impacts on all agents within the field of education whereas the mentor and teachers within the school create a social structure. 
The data suggest some students have more agency than others depending on their placement. $30 \%$ of the students felt they were not constrained at all, in the way they taught, in either of their school placements. These students felt free to try new teaching approaches: 'I had the freedom to be creative and experimental'. This freedom allowed the students to create their own pedagogy but $70 \%$ felt constrained in one of their placements, with $29 \%$ feeling constrained in both. The more fields the student teacher belongs to, the more ideas that are reflected on. The results from the questionnaire analysis illustrates the importance of placing student teachers in different schools over their PGCE year. The student learns how to satisfy both demanding mentors and ones that have a more laissez faire approach; both approaches have their merits and disadvantages but it is important for the student teacher to recognise and question the 'norm' within these different fields. If the practices in the different fields of the student teacher are not questioned they may be 'blindly' accepted and reproduced without legitimacy. 


\section{References:}

Bourdieu, P. (1990). The logic of practice. Cambridge: Polity.

Bourdieu, P. (1984), Distinction: A Social Critique of the Judgment of Taste. Cambridge, MA: Harvard University Press.

Bourdieu, P. (1986). The forms of capital. In: Richardson JG (ed.) Handbook of Theory and Research for the Sociology of Education. New York: Greenwood, 241-258.

Bourdieu, P., \& Wacquant, L. (1992). An invitation to reflexive sociology. Chicago: University of Chicago Press.

Bourdieu, P. (1977). Outline of a theory of practice. R. Nice (trans.), Cambridge: Cambridge University Press.

Bourdieu, P. (1998). Practical reason: On the theory of action. Stanford: Stanford University Press.

Burridge, P. (2014). Understanding teachers' pedagogical choice: a sociological framework combining the work of Bourdieu and Giddens. Educational Studies, 40 (5), 571-589.

Courtney, S. (2016). Post-panopticism and school inspection in England. British journal of sociology of education, 37(4), 1465-3346.

Flemmen, M. (2013). Putting Bourdieu to Work for Class Analysis. British Journal of Sociology, 64, 325-43.

Ferrare, J. J., \& Apple, M. W. (2015). Field theory and educational practice: Bourdieu and the pedagogic qualities of local field positions in educational contexts. Cambridge Journal of Education, 45(1), 43-59.

Grenfell, M. (Ed). (2008). Pierre Bourdieu: Key concepts. Stocksfield: Acumen.

Gustafsson, J., Ehren, M., Conyngham, G., McNamara, G., Altrichter, H., \& O’Hara, J. (2015). From inspection to quality: Ways in which school inspection influences change in schools. Studies in Educational Evaluation, 4747-57.

Lindgren, L., Hanberger, A., \& Lundström, U. (2016). Evaluation systems in a crowded policy space: implications for local school governance. Education Inquiry, 7, 30202.

Mansell, W. (2007). Education by numbers: the tyranny of testing. London: Politico's.

Meierdirk, C. (2016). Is reflective practice an essential component of becoming a professional teacher. Reflective Practice: International and Multidisciplinary Perspectives, 17(3), 1-10.

Nolan, K. (2012). Dispositions in the field: viewing mathematics teacher education through 
the lens of Bourdieu's social field theory. Educational Studies in Mathematics, (1/2). 201.

Saldana, J. (2009). The coding manual for qualitative researchers. Los Angeles: Sage.

Swartz, D. (2014). Theorizing fields: Fligstein, N., \& McAdam, D.: A Theory of Fields. Oxford and New York: Oxford University Press, 2012. Theory And Society, 43(6).

Ulvik, M., \& Smith, K. (2011). What characterises a good practicum in teacher education? Education Inquiry, 2 (3), 517-536.

Varga-Dobai, K. (2012). The Relationship of Researcher and Participant in Qualitative Inquiry: From "Self and Other" Binaries to the Poststructural Feminist Perspective of Subjectivity. Qualitative Report, 17.

West, A. M., \& P. Roberts, J. (2011). Accountability and Sanctions in English Schools. British Journal of Educational Studies, 59(1), 41-62.

Wood, B. E. (2013). Participatory capital: Bourdieu and citizenship education in diverse school communities. British Journal of Sociology of Education, 1-20. 